\title{
A physiology-based mathematical model for the selection of appropriate ventilator controls for lung and diaphragm protection
}

\author{
Binghao Zhang ${ }^{1}$ (1) $\cdot$ Damian Ratano ${ }^{2} \cdot$ Laurent J. Brochard $^{2,3} \cdot$ Dimitrios Georgopoulos $^{4} \cdot$ James Duffin $^{5} \cdot$ \\ Michael Long $^{6} \cdot$ Tom Schepens $^{7} \cdot$ Irene Telias $^{2,3} \cdot$ Arthur S. Slutsky $^{2,3} \cdot$ Ewan C. Goligher $^{2,5,6} \cdot$ Timothy C. Y. Chan $^{1}$
}

Received: 7 June 2019 / Accepted: 29 January 2020 / Published online: 1 February 2020

(c) Springer Nature B.V. 2020

\begin{abstract}
Mechanical ventilation is used to sustain respiratory function in patients with acute respiratory failure. To aid clinicians in consistently selecting lung- and diaphragm-protective ventilation settings, a physiology-based decision support system is needed. To form the foundation of such a system, a comprehensive physiological model which captures the dynamics of ventilation has been developed. The Lung and Diaphragm Protective Ventilation (LDPV) model centers around respiratory drive and incorporates respiratory system mechanics, ventilator mechanics, and blood acid-base balance. The model uses patient-specific parameters as inputs and outputs predictions of a patient's transpulmonary and esophageal driving pressures (outputs most clinically relevant to lung and diaphragm safety), as well as their blood $\mathrm{pH}$, under various ventilator and sedation conditions. Model simulations and global optimization techniques were used to evaluate and characterize the model. The LDPV model is demonstrated to describe a $\mathrm{CO}_{2}$ respiratory response that is comparable to what is found in literature. Sensitivity analysis of the model indicate that the ventilator and sedation settings incorporated in the model have a significant impact on the target output parameters. Finally, the model is seen to be able to provide robust predictions of esophageal pressure, transpulmonary pressure and blood $\mathrm{pH}$ for patient parameters with realistic variability. The LDPV model is a robust physiological model which produces outputs which directly target and reflect the risk of ventilator-induced lung and diaphragm injury. Ventilation and sedation parameters are seen to modulate the model outputs in accordance with what is currently known in literature.
\end{abstract}

Keywords Mechanical ventilation $\cdot$ Respiration $\cdot$ Mathematical modelling $\cdot$ Decision support

\section{Introduction}

Ewan C. Goligher and Timothy C. Y. Chan have contributed equally to this work.

Electronic supplementary material The online version of this article (https://doi.org/10.1007/s10877-020-00479-x) contains supplementary material, which is available to authorized users.

Binghao Zhang

binghao.zhang@mail.utoronto.ca

1 Department of Mechanical and Industrial Engineering, University of Toronto, 5 King's College Rd, Toronto, ON M5S 3G8, Canada

2 Interdepartmental Division of Critical Care Medicine, University of Toronto, Toronto, Canada

3 Keenan Centre for Biomedical Research, Li Ka Shing Knowledge Institute, St. Michael's Hospital, Toronto, Canada
Mechanical ventilation is a supportive intervention used to sustain respiratory function in patients with acute respiratory failure. The goals of mechanical ventilation are to ensure adequate oxygenation, carbon dioxide elimination and respiratory muscle unloading, and to decrease the oxygen cost of breathing. While mechanical ventilation has been proven

4 Department of Intensive Care Medicine, University Hospital of Heraklion, University of Crete, Heraklion, Greece

5 Department of Physiology, University of Toronto, Toronto, Canada

6 Division of Respirology, Department of Medicine, University Health Network, Toronto, Canada

7 Department of Critical Care Medicine, Antwerp University Hospital, University of Antwerp, Edegem, Belgium 
to be extremely effective for managing a variety of patients $[1,2]$, it is associated with a risk of ventilator-induced lung and diaphragm injury [2,3], especially if ventilator settings are not optimized. For instance, permitting higher plateau pressures (pressure at end-inspiration when there is no flow) or higher tidal volumes can result in dangerously high levels of lung stress and strain [4], which may lead to the development of acute lung injury [5].

The relatively recent recognition of ventilator-induced diaphragm dysfunction and the conceptualization of diaphragm-protective ventilation has significantly increased the complexity of ventilation by introducing an additional (and sometimes competing) therapeutic target: a safe level of inspiratory effort [3]. Coupled with the fact that patient characteristics can differ significantly and can change over the course of the illness, it can be challenging for even experienced clinicians to adjust ventilator settings to provide the ideal ventilation strategy individualized to the patient.

To aid in the selection of appropriate ventilator settings, numerous computerized decision support systems (CDSSs) have been developed. Earlier CDSSs were mostly rule-based systems that used clinical heuristics-simplified decisionmaking strategies that use only a few available parametersto select ventilator settings [6]. Rule-based systems attempt to achieve specified ventilation targets $[7,8]$ or maintain a patient's ventilatory parameters within a predetermined comfort range [9]. They are designed to help clinicians by providing them with suggestions on what actions to take when the conditions for the actions are met. However, these systems do not consider the physiological differences between patients, or even the same patient at different times in the disease process, and thus do not ensure that the suggested actions are optimal for each individual patient at any point in time. In addition, rule-based systems do not provide clinicians with insight into a patient's physiological state. In contrast to rule-based CDSSs, physiologically based CDSSs are useful for optimizing ventilator settings for individualized patient safety, predicting the effects of various ventilation strategies, and monitoring a patient's overall physiological status [10].

To date, existing physiologically-based CDSSs have not specified patient respiratory effort or transpulmonary pressure (a more direct measure of dynamic lung stress than tidal volume) as targets for ventilation. Some physiologically-based CDSSs focus primarily on modeling pulmonary gas exchange and ensuring safe and adequate oxygenation and $\mathrm{CO}_{2}$ elimination [11-15]. Others integrate lung protection as a ventilation target but rely on indirect parameters of lung stress (tidal volume) and patient effort (respiratory rate, oxygen consumption) [16]. Preliminary data suggest that a CDSS designed in this way achieves safe ventilatory conditions in patients who are weaning from mechanical ventilation [17]. It is uncertain whether this approach would effectively avoid both overassistance and under-assistance diaphragm myotrauma- $[3,18]$. Moreover, existing systems do not account for the effects of sedation on respiratory drive and inspiratory effort [19-21]. Finally, existing CDSSs operating under pressure support ventilation, a common mode of assisted ventilation, do not incorporate the expiratory cycling threshold; this important setting determines patient-ventilator synchrony and can substantially modify the volume delivered by the ventilator. Incorporating this setting into the CDSS might significantly enhance the effectiveness and tolerability of ventilation.

In this paper, we propose a novel integrated physiological model that can provide the foundation for a CDSS targeting both lung and diaphragm protection under two paradigmatic modes of assisted ventilation, pressure support and proportional-assist ventilation. The latter was included as a prototypical mode where ventilator support is proportional to patient effort. Compared to existing models, our model is the first to (1) focus on the effects of respiratory effort on lung as well as diaphragm injury; (2) output target indicators theorized to directly reflect the risk of lung and diaphragm injury [18, 22-24]; (3) consider the impact of propofol, a common drug used to sedate patients under ventilatory care; (4) incorporate an expiratory cycling threshold under pressure support mode. While mathematical equations describing the dynamics of these four factors exist in the literature, to the best of our knowledge this is the first attempt to integrate them together into a single cohesive mathematical model. Section 2 describes the individual systems incorporated into the model, how they are integrated, and how outputs are generated. Section 3 demonstrates the validity and robustness of the model through a simulation study. Section 4 offers a discussion of the rationale for the model, how it compares to existing models, the results of the simulation study, and the model's limitations.

\section{A lung and diaphragm-protective ventilation model}

The proposed model is termed the Lung and DiaphragmProtective Ventilation (LDPV) model. The parameters of the model are evaluated under steady-state conditions in the presence of anesthesia, with the overall system consisting of five individual components:

1. Respiratory drive

2. Pharmacokinetics of propofol

3. Acid-base homeostasis

4. Ventilator mechanics

5. Lung and respiratory muscle mechanics 
Figure 1 illustrates how each component interacts with the rest of the model. Individual components require either patient-specific parameters, control parameters or calculated parameters as inputs. Patient-specific input parameters are values that vary from patient to patient. These parameters can either be relatively stable within patients over brief periods (such as lung elastance and central chemoreceptor sensitivity) or change throughout the duration of the intervention (such as respiratory frequency). Control parameters are values that clinicians can directly modify. In the LDPV model, the control parameters are: ventilator mode, inspiratory support level, flow-cycle threshold, propofol infusion rate and propofol infusion duration. Calculated parameters, such as $\mathrm{CO}_{2}$ partial pressure, are intermediate parameter values determined by system components using patient and control parameters. Each component produces either calculated parameters or the final model outputs indicators. The system has three output indicators: transpulmonary driving pressure (the swing in transpulmonary pressure between end-inhalation and end-expiration, $\Delta P_{\mathrm{L}}$ ), esophageal driving pressure (the swing in esophageal pressure between endinhalation and end-expiration, $\left.\Delta P_{\mathrm{ES}}\right)$ and $\mathrm{pH}$.

Section 2.1-2.5 provide mathematical descriptions of each system component. The patient parameters necessary for each component are given in Table 1. All relevant mathematical symbols are defined in Online Resource 1. The full solution process is detailed in Online Resource 2.4 .

\subsection{Respiratory drive}

We model spontaneous respiration using three components [25]: central chemoreflex drive $\left(D_{\mathrm{c}}\right)$, peripheral chemoreflex drive $\left(D_{\mathrm{p}}\right)$, and a wakefulness drive $\left(D_{\mathrm{w}}\right)$, quantified in litres/min. The sum of the three describes the overall desired minute ventilation of the patient $\left(V_{\mathrm{e}, \text { patient }}\right)$.

$V_{e, \text { patient }}=D_{c}+D_{p}+D_{w}$.

As the model is evaluated under steady-state conditions, the response speed difference between the central and peripheral receptors does not influence the model and is thus not considered. In addition, since the model is evaluated under the presence of anesthesia, $D_{\mathrm{w}}$ is assumed to be zero. The central and peripheral chemoreflex drives are given by [25]

$D_{c}=\max \left\{0, S_{c}\left(\left[H^{+}\right]-T_{c}\right)\right\}$

and

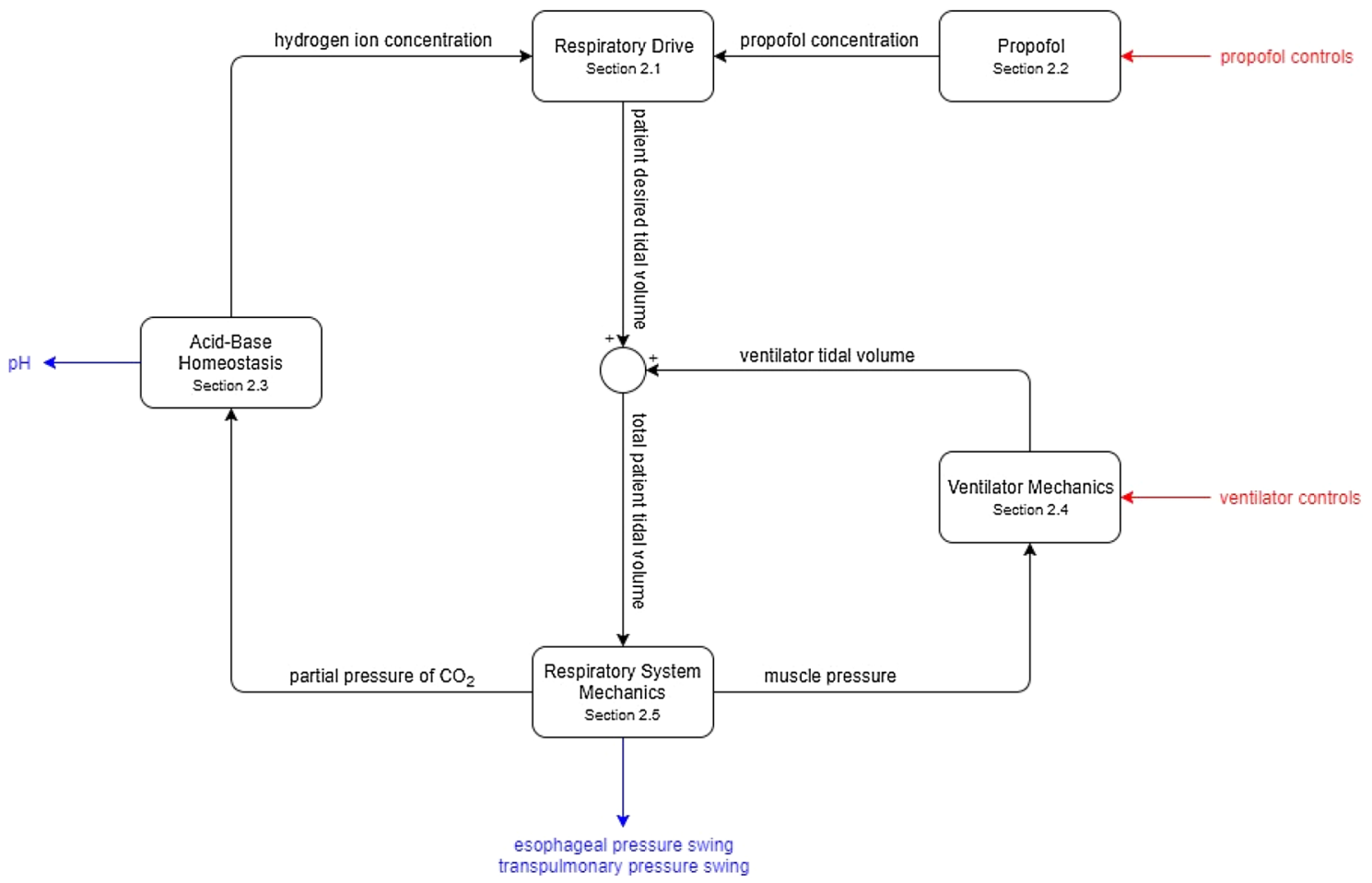

Fig. 1 The five components of the LDPV model. Only factors which facilitate interaction between the components are displayed on the arrows. Calculated parameters (hydrogen ion concentration, propofol concentration, patient desired tidal volume, ventilator tidal volume, total patient tidal volume, partial pressure of $\mathrm{CO}_{2}$, muscle pressure) are denoted in black. Control parameters (propofol controls, ventilator controls) are denoted in red. Output indicators are denoted in blue ( $\mathrm{pH}$, esophageal pressure swing, transpulmonary pressure swing) 
Table 1 Inputs and outputs of the LDPV model

\begin{tabular}{|c|c|c|}
\hline Variable & Description & Units \\
\hline \multicolumn{3}{|c|}{ Patient parameters for propofol } \\
\hline WGT & Patient weight & $\mathrm{kg}$ \\
\hline HGT & Patient height & $\mathrm{m}$ \\
\hline AGE & Patient age & Years \\
\hline PMA & Patient post-menstrual age & Weeks \\
\hline SEX & Patient sex & 1 if male \\
\hline OPIATES & Presence of opiates & 1 if yes \\
\hline \multicolumn{3}{|c|}{ Patient parameters for respiratory drive } \\
\hline$P_{\mathrm{O} 2}$ & Partial pressure of $\mathrm{O}_{2}$ & $\mathrm{mmHg}$ \\
\hline$S_{0}$ & Peripheral receptor sensitivity in hyperoxia & $\mathrm{L} \min ^{-1}\left(\mathrm{nM} \mathrm{L}^{-1}\right)^{-1}$ \\
\hline$P_{0}$ & $\mathrm{P}_{\mathrm{O}} 2$ at max peripheral sensitivity & $\mathrm{mmHg}$ \\
\hline$A$ & Peripheral receptor area constant & $\mathrm{L} \min ^{-1} \mathrm{mmHg}\left(\mathrm{nM} \mathrm{L}^{-1}\right)^{-1}$ \\
\hline$T_{\mathrm{c}}$ & Threshold of central receptors & $\mathrm{nM} \mathrm{L}^{-1}$ \\
\hline$T_{\mathrm{p}}$ & Threshold of peripheral receptors & $\mathrm{nM} \mathrm{L}^{-1}$ \\
\hline$D_{\mathrm{w}}$ & Wakefulness drive & $\mathrm{L} \min ^{-1}$ \\
\hline \multicolumn{3}{|c|}{ Patient parameters for respiratory and ventilator mechanics } \\
\hline$F_{\mathrm{R}}$ & Respiratory frequency & Breaths $\min ^{-1}$ \\
\hline$R$ & Resistance of respiratory system & $\mathrm{cmH}_{2} \mathrm{O} \mathrm{L}^{-1} \mathrm{~s}$ \\
\hline$C_{1}$ & Lung compliance & $\mathrm{L} \mathrm{cmH}_{2} \mathrm{O}^{-1}$ \\
\hline$C_{\mathrm{cw}}$ & Chest wall compliance & $\mathrm{L} \mathrm{cmH}_{2} \mathrm{O}^{-1}$ \\
\hline PEEPi & Intrinsic PEEP & $\mathrm{cmH}_{2} \mathrm{O}$ \\
\hline $\mathrm{I}: \mathrm{E}$ & Inspiratory-expiratory ratio & None \\
\hline$V_{\mathrm{CO} 2}$ & Metabolic production/clearance of $\mathrm{CO}_{2}$ & $\mathrm{~L} \min ^{-1}$ \\
\hline$V_{\mathrm{D}, \text { anat }}$ & Anatomical dead space & $\mathrm{L}$ \\
\hline$V_{\mathrm{D}, \text { alvratio }}$ & Alveolar dead space ratio & None \\
\hline \multicolumn{3}{|c|}{ Patient parameters for blood acid-base } \\
\hline$\left[\mathrm{Na}^{+}\right]$ & Sodium ion concentration & $\mathrm{M} \mathrm{L}^{-1}$ \\
\hline$\left[\mathrm{K}^{+}\right]$ & Potassium ion concentration & $\mathrm{M} \mathrm{L}^{-1}$ \\
\hline$\left[\mathrm{Ca}^{2+}\right]$ & Calcium ion concentration & $\mathrm{ML}^{-1}$ \\
\hline$\left[\mathrm{Mg}^{2+}\right]$ & Magnesium ion concentration & $\mathrm{ML}^{-1}$ \\
\hline$\left[\mathrm{Cl}^{-}\right]$ & Chloride ion concentration & $\mathrm{M} \mathrm{L}^{-1}$ \\
\hline Alb & Albumin concentration & $\mathrm{g} \mathrm{dL}^{-1}$ \\
\hline$P \mathrm{i}$ & Inorganic phosphate concentration & $\mathrm{ML}^{-1}$ \\
\hline \multicolumn{3}{|c|}{ Propofol controls } \\
\hline$D$ & Propofol dose rate & $\mu \mathrm{g} \mathrm{kg}^{-1} \min ^{-1}$ \\
\hline$T_{\text {inf }}$ & Infusion time & $\min$ \\
\hline$t_{\mathrm{D}}$ & Time of last dose & $\min$ \\
\hline \multicolumn{3}{|c|}{ Ventilator controls } \\
\hline PSV & Pressure support & $\mathrm{cmH}_{2} \mathrm{O}$ \\
\hline$x_{\mathrm{TH}}$ & Flow-cycle proportion & None \\
\hline$k$ & Proportional assist ventilation factor & None \\
\hline \multicolumn{3}{|c|}{ Output indicators } \\
\hline$\Delta P_{\mathrm{L}}$ & Driving transpulmonary pressure (static conditions) & $\mathrm{cmH}_{2} \mathrm{O}$ \\
\hline$\Delta P_{\mathrm{ES}}$ & Esophageal pressure change (static conditions) & $\mathrm{cmH}_{2} \mathrm{O}$ \\
\hline $\mathrm{pH}$ & Arterial blood $\mathrm{pH}$ & None \\
\hline
\end{tabular}


$D_{p}=\max \left\{0, S_{p}\left(\left[H^{+}\right]-T_{p}\right)\right\}$,

respectively. The chemoreflex drives are determined by the hydrogen ion concentration $\left(\left[\mathrm{H}^{+}\right]\right)$, patient-specific receptor sensitivities $\left(S_{\mathrm{c}}, S_{\mathrm{p}}\right)$ and patient-specific receptor thresholds $\left(T_{\mathrm{c}}, T_{\mathrm{p}}\right)$. Since $\left[\mathrm{H}^{+}\right]$is heavily affected by the partial pressure of arterial $\mathrm{CO}_{2}\left(P_{\mathrm{CO} 2}\right.$, see Sect. 2.3), $P_{\mathrm{CO} 2}$ is a crucial determinant of respiratory drive. In addition, below the receptor thresholds, no respiratory drive is generated. Hence, a max function is needed to constrain $D_{\mathrm{c}}$ and $D_{\mathrm{p}}$ to non-negative values.

Peripheral receptor sensitivity is determined by a variety of patient-specific parameters [25], most notably the partial pressure of arterial $\mathrm{O}_{2}\left(P_{\mathrm{O} 2}\right)$. In contrast, evidence suggests that the sensitivity of the central receptors is heavily modulated by propofol levels $\left(C_{\text {prop }}\right)$ [19]. To estimate the influence of $C_{\text {prop }}$ on $S_{\mathrm{c}}$, we performed linear regression on the only existing (but very limited) clinical data relating to these variables [19], yielding the following relationship:

$S_{c}=-0.469 C_{\text {prop }}+1.492$.
As the available clinical data measured receptor sensitivity in response to $P_{\mathrm{CO} 2}$ rather than $\left[\mathrm{H}^{+}\right]$, the modified Stewart acid-base model [25] was used to generate a conversion factor to modify the linear regression. While the factor was found to increase with increasing $P_{\mathrm{CO} 2}$ levels across a range of applicable $P_{\mathrm{CO} 2}$ values $(20-70 \mathrm{mmHg}$ ), it only varied from 1.03 to 1.09 . Hence, to reduce complexity, a fixed value of 1.06 was used. Multiplying this factor through the linear regression model in Eq. (4) yields the following relation between central receptor sensitivity and $C_{\text {prop: }}$ :

$S_{c}=-0.497 C_{\text {prop }}+1.580$.

\subsection{Pharmacokinetic model of propofol}

We used a previously described pharmacokinetic (PK) model [26] to simulate the effects of propofol on respiration (Fig. 2). As seen in Fig. 3, the propofol PK model incorporates both patient-specific input parameters and control parameters (rate and duration of infusion), and outputs a predicted concentration of propofol in the patient's blood $\left(C_{\text {prop }}\right)$ (Figs. 4, 5, 6). This concentration is then

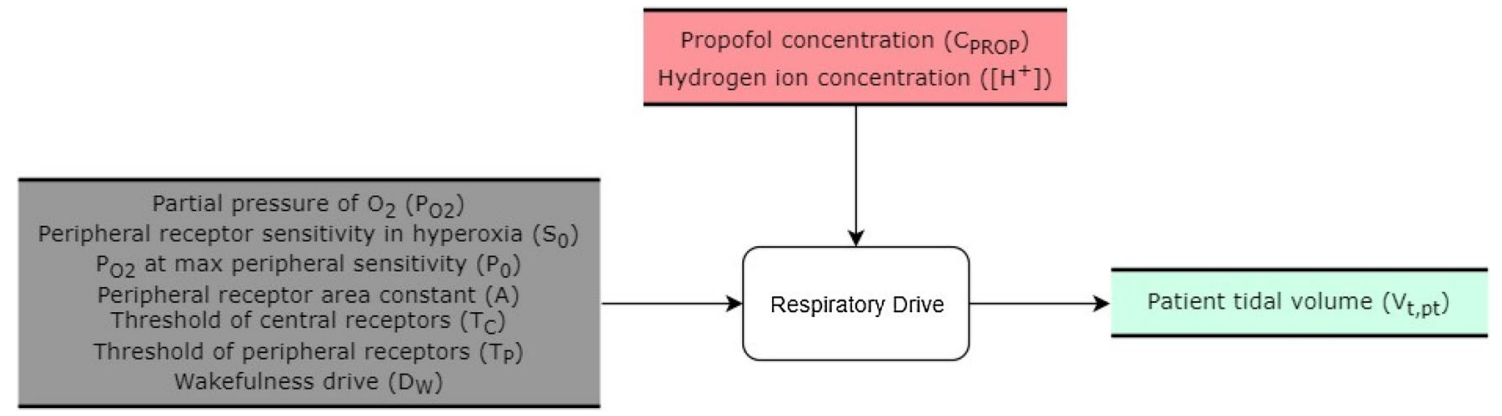

Fig. 2 The patient's respiratory control system requires patient (gray) and calculated (red) inputs and outputs patient tidal volume (green). Only direct inputs are included

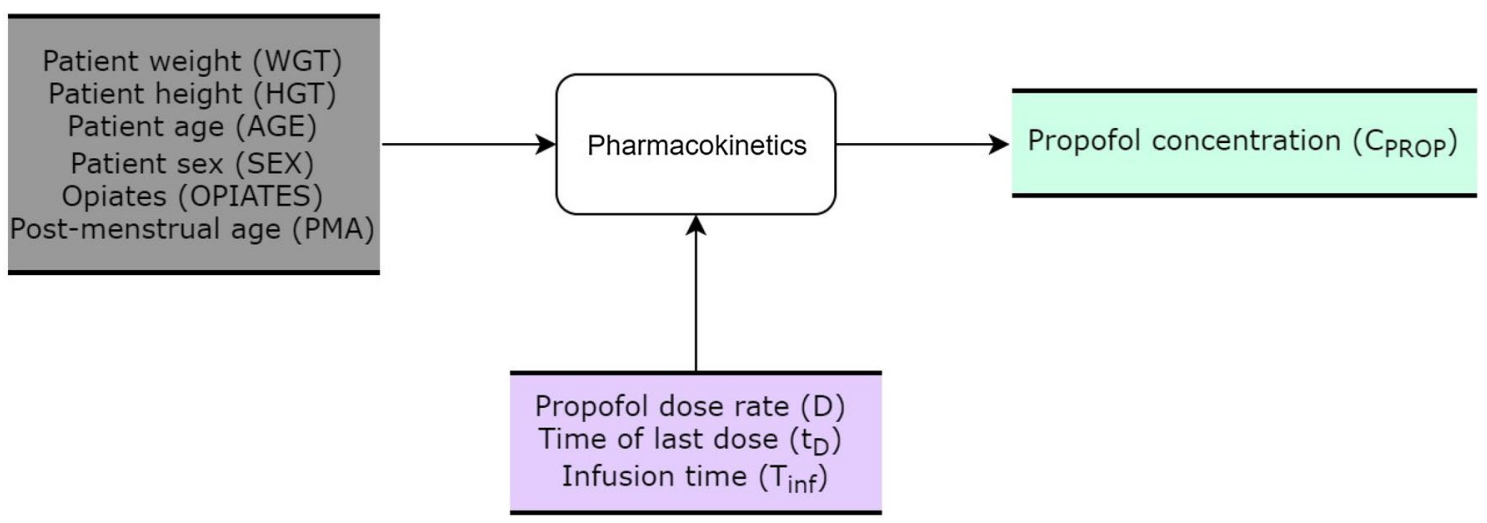

Fig. 3 The propofol pharmacokinetic system takes in several patient (gray) and control parameters as inputs (blue) and outputs propofol concentration (green). Only direct inputs are included 


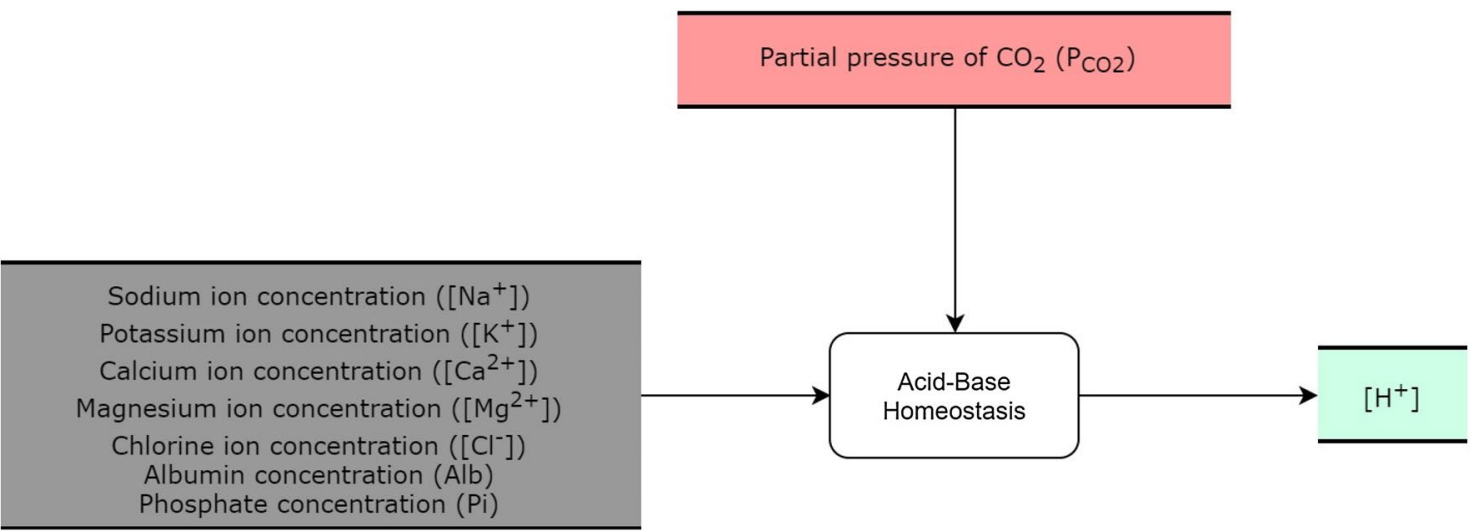

Fig. 4 The acid-base model requires patient (gray) and calculated (red) inputs and outputs pH (green). Only direct inputs are included

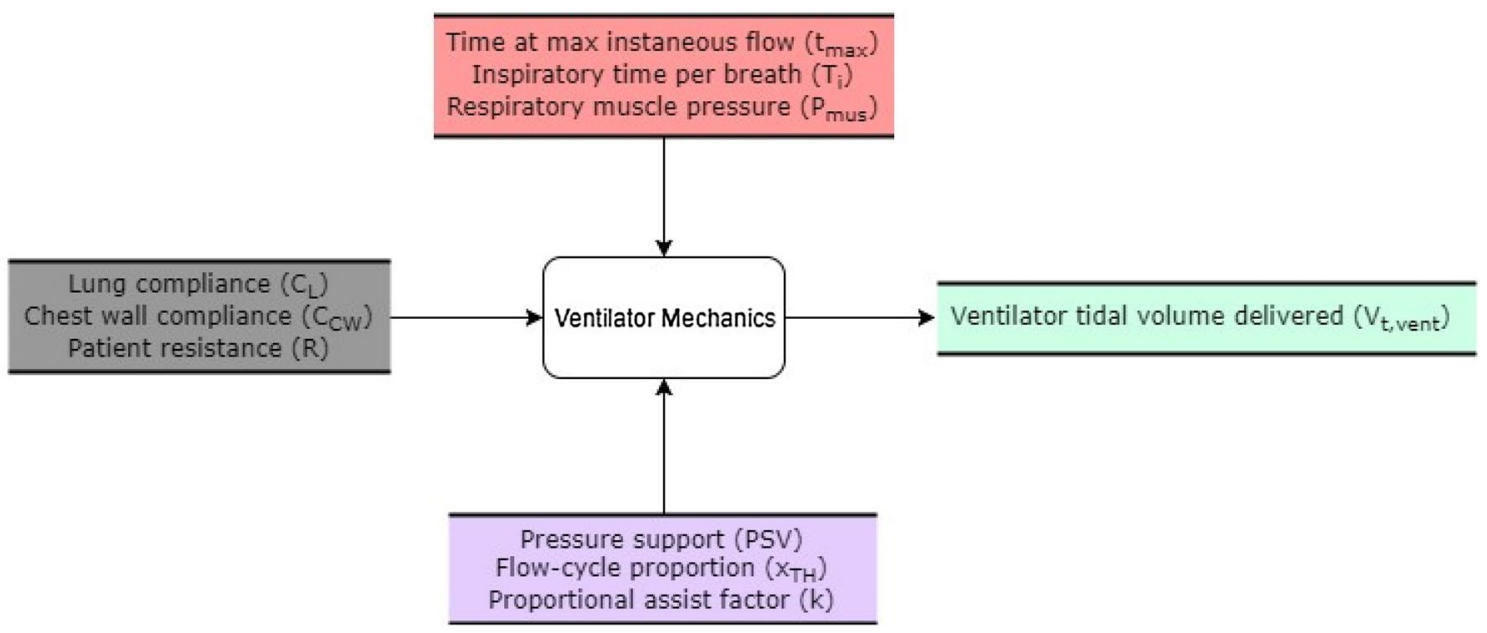

Fig. 5 The ventilator system requires patient (gray), control (blue) and calculated (red) inputs and outputs ventilator tidal volume (green). Only direct inputs are included

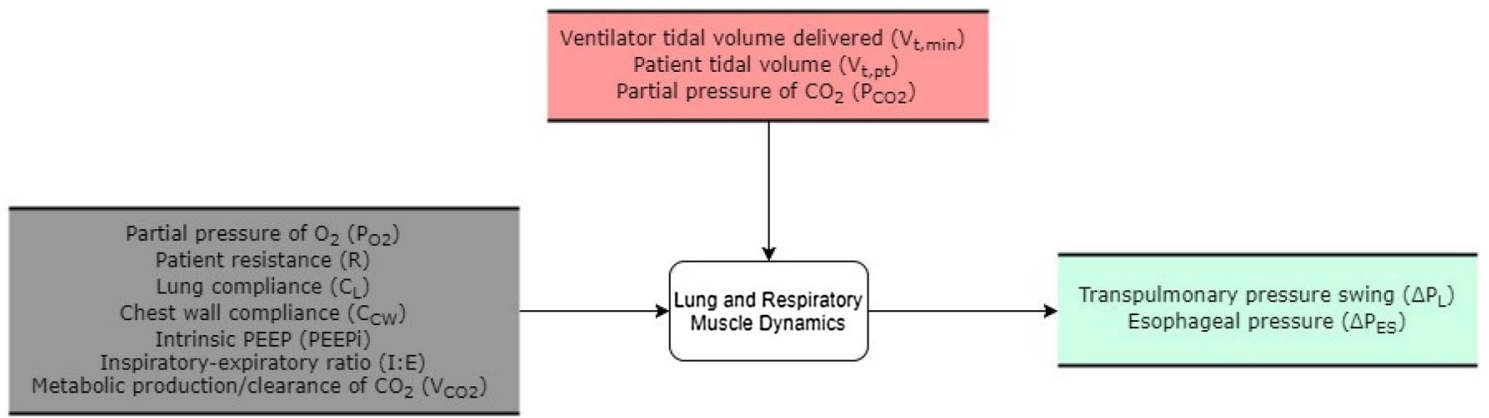

Fig. 6 The lung and respiratory muscle system requires patient (gray) and calculated (red) inputs and outputs patients' driving transpulmonary pressure $\left(\Delta P_{\mathrm{L}}\right)$ and esophageal pressure $\left(\Delta P_{\mathrm{ES}}\right)$ swings (under steady-state conditions). Only direct inputs are included 
used to determine the impact of propofol on respiration. The complete mathematical details regarding the incorporation of this model can be found in Online Resource 2.

\subsection{Acid-base homeostasis}

We used a modified version of the Stewart acid-base model [25], shown in Eq. (6). The Stewart acid-base model describes arterial blood and uses physiologically interpretable parameters to provide greater quantitative insight into acid-base disorders than other acid-base models $[27,28]$, at the expense of additional complexity. The modified version we use substitutes albumin and phosphate for total protein, addressing some of the weaknesses of the original Stewart model [29]. $\left[\mathrm{H}^{+}\right]$, which determines $\mathrm{pH}$, is calculated via the following equation, using $P_{\mathrm{CO} 2}$, strong ion difference $(S I D)$, phosphate $\left(P_{\mathrm{i}}\right)$, and albumin (Alb):

$$
\begin{gathered}
S I D+\left[H^{+}\right]-\frac{K_{c} P_{C O 2}}{\left[H^{+}\right]}-\left(21 A l b \cdot \frac{10}{66500}-\left[H^{+}\right] \cdot \frac{16 A l b \cdot \frac{10}{66500}}{K_{h}+\left[H^{+}\right]}\right)- \\
\frac{2 K_{3} K_{c} P_{C O 2}}{\left[H^{+}\right]^{2}}-\frac{K_{w}}{\left[H^{+}\right]}-P i \cdot\left(2-\frac{\left[H^{+}\right]}{K_{2}+\left[H^{+}\right]}\right)=0 .
\end{gathered}
$$

The equation also uses several constants, namely the ion product for water $\left(\mathrm{K}_{w}\right)$, phosphoric acid dissociation constant $\left(\mathrm{K}_{2}\right)$, carbonate dissociation constant $\left(\mathrm{K}_{3}\right)$, histidine dissociation constant $\left(\mathrm{K}_{h}\right)$, and equilibrium and solubility constants $\left(\mathrm{K}_{c}\right)$.

\subsection{Ventilator mechanics}

Our LDPV model estimates the contribution of the ventilator to total tidal volume under both pressure support ventilation (PSV) and proportional assist ventilation (PAV) modes.

\subsubsection{Pressure support ventilation mode}

Under PSV, the minimal tidal volume delivered by the ventilator in the quasi-absence of patient effort.

$\left(V_{\mathrm{t}, \text { vent }}\right)$ is related to the patient's resistance $(R)$ and total elastance $\left(E_{\mathrm{RS}}\right)$ and is represented as [30]

$V_{t, v e n t}=\frac{P S V-V_{T H} R}{E_{R S}}$.

The control parameter $P S V$ represents the inspiratory pressure above PEEP applied by the ventilator to deliver a tidal breath [30]. Under pressure support, the ventilator delivers the set inspiratory pressure when a patient triggers the ventilator. To terminate inspiratory flow, the flow-cycle threshold $\left(V_{\mathrm{TH}}\right)$ must be reached [31]. While this value is typically chosen to be $25 \%$ of the inspiratory peak flow, this percentage can be modified at the discretion of the clinician according to the patient's mechanics $[32,33]$ and is thus also included as a control parameter in the LDPV model as the flow-cycle proportion $\left(x_{\mathrm{TH}}\right)$. The mathematical derivation required to determine the peak flow, and hence the flow-cycle threshold, is covered in Online Resource 2.2.

\subsubsection{Proportional assist ventilation mechanics}

Under PAV mode, the pressure delivered by the ventilator is set as a fraction of the total pressure applied to the respiratory system resulting from the combined pressures generated by the ventilator and the patient [34]. In PAV, ventilator inspiratory flow is zero when patient inspiratory flow ceases. Hence, the tidal volume specifically attributed to the ventilator $\left(V_{\mathrm{t}, \mathrm{vent}}\right)$ is computed as:

$V_{t, v e n t}=\frac{k}{1-k} \cdot V_{t, \text { patient }}$.

In this case, the clinician controls the proportional assist factor $(k)$, which scales the pressure and flow (and resulting tidal volume) delivered by the ventilator in relation to the tidal volume generated by the patient's respiratory effort $\left(V_{\text {t,patient }}\right)$. The factor $k$ ranges between 0 and 1 and determines the proportion of total ventilation delivered by the ventilator.

\subsection{Lung and respiratory muscle mechanics}

One of the key equations governing gas exchange is the minute ventilation equation [34]:

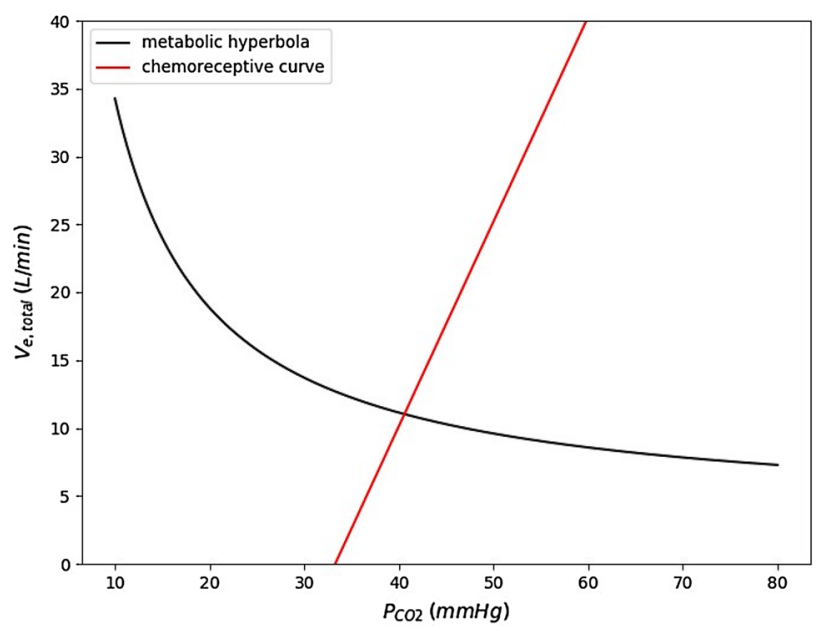

Fig. 7 A respiratory response curve showing the intersection between the chemoreceptive drive (Eq. (1), denoted by red) and the alveolar equation (Eq. (9), denoted by black). This relationship applies during sleep or sedation, when wakefulness drive is zero 


$$
V_{e, \text { total }}=\frac{K \dot{V}_{C O 2}}{P_{C O 2}\left(1-\frac{V_{D, \text { anat }}}{V_{t, \text { total }}}-V_{D, \text { alvratio }}\right)} .
$$

This equation relates a patient's total minute ventilation $\left(V_{\text {e,total }}\right)$ to their arterial $P_{\mathrm{CO} 2}$ levels and their systemic $\mathrm{CO}_{2}$ production $\left(V_{\mathrm{CO} 2}\right)$, while taking into account their anatomic dead space volume $\left(V_{\mathrm{D} \text {,anat }}\right)$ and alveolar dead space fraction $\left(V_{\mathrm{D} \text {,alvratio }}\right.$, ratio between alveolar dead space and tidal volume). The proportionality constant $(K=0.863)$ serves to correct for temperature and humidity [34]. The minute ventilation equation governs the relationship between $P_{\mathrm{CO} 2}$ and minute ventilation and is represented as the metabolic hyperbola in Fig. 7. The intersection between the metabolic hyperbola and the chemoreceptive drive curve determines the steady state conditions for minute ventilation when the wakefulness drive to breathe is zero.

To estimate the driving transpulmonary pressure $\left(\Delta P_{\mathrm{L}}\right)$ and esophageal pressure $\left(\Delta P_{\mathrm{ES}}\right)$ swings obtained at a given level of minute ventilation and ventilator support under static conditions, the LDPV model applies the equation of motion for the respiratory system, a simple, single compartment representation of the respiratory system $[35,36]$. The mean inspiratory flow generated by the patient can be represented as $V_{\mathrm{t} \text {,patient }} / T_{\mathrm{i}}$, where $V_{\mathrm{t} \text {,patient }}$ is the tidal volume resulting from a patient's respiratory drive. The respiratory muscle pressure $\left(P_{m u s}\right)$ can then be related to the intrinsic partial positive end-expiratory pressure (PEEPi), $V_{\mathrm{t} \text {,patient, }}$, $R, E_{\mathrm{RS}}$, and $T_{\mathrm{i}}$ :

$P_{\text {mus }}=\frac{V_{t, \text { atient }}}{T_{i}} R+V_{t, \text { patient }} E_{R S}+$ PEEPi.

Using the calculated values of $P_{\text {mus }}$ and total tidal volume $\left(V_{\mathrm{t} \text {,total }}=V_{\mathrm{t} \text {,patient }}+V_{\mathrm{t} \text {,vent }}\right)$ along with lung $\left(E_{\mathrm{L}}\right)$ and chest wall $\left(E_{\mathrm{CW}}\right)$ elastance, a patient's $\Delta P_{\mathrm{L}}$ and $\Delta P_{\mathrm{ES}}$ can be calculated as

$\Delta P_{L}=V_{t, t o t a l} E_{L}$

and

$\Delta P_{E S}=V_{t, \text { total }} E_{C W}-P_{\text {mus }}$

\section{Model simulations}

We conducted a series of simulations to test the functionality and robustness of the model using Python 3.6.0, with Newton's method being used to solve the system of equations. Initial estimates for the intermediate variables used in the calculations are shown in Table 2.
Table 2 Initial solution estimates of the intermediate variables associated with the LDPV model

\begin{tabular}{|c|c|}
\hline Variable & Initial estimate \\
\hline \multicolumn{2}{|c|}{ Initial solution estimates } \\
\hline$S_{\mathrm{c}}$ & $1 \mathrm{~L} \mathrm{~min}^{-1}\left(\mathrm{nM} \mathrm{L}^{-1}\right)^{-1}$ \\
\hline$S_{\mathrm{p}}$ & $1 \mathrm{~L} \mathrm{~min}^{-1}\left(\mathrm{nM} \mathrm{L}^{-1}\right)^{-1}$ \\
\hline$D_{\mathrm{c}}$ & $2 \mathrm{~L} \mathrm{~min}^{-1}$ \\
\hline$D_{\mathrm{p}}$ & $2 \mathrm{~L} \mathrm{~min}^{-1}$ \\
\hline$V_{\text {e,patient }}$ & $3 \mathrm{~L} \mathrm{~min}^{-1}$ \\
\hline$V_{\mathrm{e}, \min }$ & $3 \mathrm{~L} \mathrm{~min}^{-1}$ \\
\hline$V_{\mathrm{e}, \text { total }}$ & $6 \mathrm{~L} \mathrm{~min}^{-1}$ \\
\hline$P_{\mathrm{CO} 2}$ & $30 \mathrm{mmHg}$ \\
\hline$V_{\mathrm{t} \text {,patient }}$ & $0.5 \mathrm{~L}$ \\
\hline$V_{\mathrm{t}, \text { total }}$ & $0.5 \mathrm{~L}$ \\
\hline$V_{\mathrm{t}, \text { vent }}$ & $0.3 \mathrm{~L}$ \\
\hline$V_{\mathrm{TH}}$ & $0.2 \mathrm{~L} \mathrm{~s}^{-1}$ \\
\hline$t_{\max }$ & $0.3 \mathrm{~s}$ \\
\hline$T_{\mathrm{i}}$ & $1 \mathrm{~s}$ \\
\hline$P_{\text {mus }}$ & $3 \mathrm{cmH}_{2} \mathrm{O}$ \\
\hline$E_{\mathrm{RS}}$ & $20 \mathrm{cmH}_{2} \mathrm{OL} \mathrm{L}^{-1}$ \\
\hline SID & $0 \mathrm{M} \mathrm{L}^{-1}$ \\
\hline$\left[\mathrm{H}^{+}\right]$ & $4-10^{-8} \mathrm{M} \mathrm{L}^{-1}$ \\
\hline$\Delta P_{\mathrm{L}}$ & $8 \mathrm{cmH}_{2} \mathrm{O}$ \\
\hline$\Delta P_{\mathrm{ES}}$ & $10 \mathrm{cmH}_{2} \mathrm{O}$ \\
\hline $\mathrm{pH}$ & 7.4 \\
\hline
\end{tabular}

Table 3 Nominal values, ranges and step-sizes of patient parameters used in model simulations

\begin{tabular}{lclll}
\hline Variable & Range & Step-size & Nominal value & Units \\
\hline \multicolumn{4}{l}{ Nominal values, ranges and step-sizes for input variables } \\
$P_{\mathrm{O} 2}$ & $60-100$ & \pm 5 & 100 & $\mathrm{mmHg}$ \\
$F_{\mathrm{R}}$ & $15-35$ & \pm 5 & 20 & $\mathrm{Breath} \mathrm{min}^{-1}$ \\
$R$ & $4-10$ & \pm 1 & 5 & $\mathrm{cmH}_{2} \mathrm{O} \mathrm{L} \mathrm{L}^{-1} \mathrm{~s}$ \\
$C_{1}$ & $0.01-0.2$ & \pm 0.05 & 0.075 & $\mathrm{~L} \mathrm{cmH}_{2} \mathrm{O}^{-1}$ \\
$C_{\mathrm{cw}}$ & $0.03-0.2$ & \pm 0.05 & 0.125 & $\mathrm{~L} \mathrm{cmH}_{2} \mathrm{O}^{-1}$ \\
$V_{\mathrm{CO} 2}$ & $0.15-0.3$ & \pm 0.05 & 0.250 & $\mathrm{~L} \mathrm{~min}{ }^{-1}$ \\
$V_{\mathrm{D} \text {,anat }}$ & $0.1-0.16$ & \pm 0.02 & 0.12 & $\mathrm{~L}$ \\
$V_{\mathrm{D} \text {,alvratio }}$ & $0.1-0.4$ & \pm 0.05 & 0.3 & $\mathrm{None}$ \\
PSV & $0-20$ & \pm 3 & 5 & $\mathrm{cmH}_{2} \mathrm{O}$ \\
$x_{\mathrm{TH}}$ & $0.1-0.5$ & \pm 0.05 & 0.25 & None \\
$k$ & $0.1-0.9$ & \pm 0.1 & 0.5 & None \\
$C_{\text {prop }}$ & $0-2$ & \pm 0.25 & 0 & $\mu \mathrm{g} \mathrm{mL}$ \\
\hline
\end{tabular}

\subsection{Simulation method}

\subsubsection{Patient response to manipulation of model control variables}

We first illustrate the model's interpretation of patient response to varying levels of ventilatory support and propofol. Nominal parameter values (Tables 3 and 4) were based 
Table 4 Nominal values of static input variables used in model simulations and their input ranges for the Morris sensitivity analysis

\begin{tabular}{|c|c|c|c|}
\hline Variable & Nominal value & Input range for morris analysis & Units \\
\hline \multicolumn{4}{|c|}{ Values of static inputs } \\
\hline$S_{0}$ & $0 \mathrm{~L}$ & $0-5$ & $\mathrm{~L} \min ^{-1}\left(\mathrm{nM} \mathrm{L}{ }^{-1}\right)^{-1}$ \\
\hline$P_{0}$ & 30 & $10-50$ & $\mathrm{mmHg}$ \\
\hline$A$ & $17.8 \mathrm{~L}$ & $10-30$ & $\mathrm{~L} \min ^{-1} \mathrm{mmHg}\left(\mathrm{nM} \mathrm{L}^{-1}\right)^{-1}$ \\
\hline$T_{\mathrm{c}}$ & 31.8 & $20-45$ & $\mathrm{nM} \mathrm{L}^{-1}$ \\
\hline$T_{\mathrm{p}}$ & 34.6 & $20-45$ & $\mathrm{nM} \mathrm{L} \mathrm{L}^{-1}$ \\
\hline$D_{\mathrm{w}}$ & 0 & N/A (assuming sedation) & $\mathrm{L} \min ^{-1}$ \\
\hline $\mathrm{I}: \mathrm{E}$ & 0.5 & $0.3-1$ & None \\
\hline PEEPi & 0 & $0-10$ & $\mathrm{cmH}_{2} \mathrm{O}$ \\
\hline$\left[\mathrm{Na}^{+}\right]$ & 0.139 & $0.125-0.158$ & $\mathrm{ML}^{-1}$ \\
\hline$\left[\mathrm{K}^{+}\right]$ & 0.0043 & $0.0028-0.0065$ & $\mathrm{M} \mathrm{L}^{-1}$ \\
\hline$\left[\mathrm{Ca}^{2+}\right]$ & 0.0012 & $0.075-0.125$ & $\mathrm{ML}^{-1}$ \\
\hline$\left[\mathrm{Mg}^{2+}\right]$ & 0.00085 & $0.0004-0.0015 \mathrm{M}$ & $\mathrm{M} \mathrm{L}^{-1}$ \\
\hline$\left[\mathrm{C}^{-}\right]$ & 0.105 & $0.075-0.125$ & $\mathrm{ML}^{-1}$ \\
\hline Alb & 4.5 & $1.5-4.5$ & $\mathrm{~g} \mathrm{dL}^{-1}$ \\
\hline$P \mathrm{i}$ & 0.0012 & $0.0004-0.002$ & $\mathrm{M} \mathrm{L}^{-1}$ \\
\hline
\end{tabular}

on clinical experience or values found in literature [25, 27]. Although $C_{\text {prop }}$ is an intermediate variable which depends on several pharmacokinetic related patient-specific parameters (height, weight, dose, etc.), it was modified directly in simulations for simplicity.

The $\mathrm{CO}_{2}$ response curve under different levels of assist (for both PSV and PAV modes) and at different propofol levels was determined by individually plotting the minute ventilation equation and patient response as found through the model. Simulations to validate the effect of each control parameter on the output indicators were also conducted, with full details and results available in Online Resource 3.1 and 4.

\subsubsection{Parameter sensitivity}

To further validate the model, a global sensitivity analysis was performed on all patient-specific and control parameters. Due to its low computational demand, the sensitivity analysis was performed using the Morris method [37] as implemented by Campolongo et al. [38]. All parameters were varied across the ranges stated in Tables 3 and 4. No static or nominal values were used for the sensitivity analysis. The full details and results of the sensitivity analysis can be found in Online Resource 3.2 and 4.2.

\subsubsection{Robustness of the model}

To demonstrate model robustness, we show that it produces outputs that remain within physiologically plausible limits for all possible combinations of clinically relevant inputs. These limits were determined based on clinical experience and are as follows:
$0 \leq \Delta P_{L} \leq 40.0$

$-40.0 \leq \Delta P_{E S} \leq 0$

$7.10 \leq p H \leq 7.60$

To determine extremal values of the model outputs, we solved two multi-objective optimization problems:

$\underset{\mathbf{x}}{\operatorname{maximize}}\left\{\Delta P_{L}(\mathrm{x}),\left|\Delta P_{E S}(\mathrm{x})\right|, p H(\mathrm{x})\right\} \#$

subject to $\mathbf{l} \leq \mathrm{x} \leq \mathbf{u} \#$

$\underset{\mathrm{x}}{\operatorname{minimize}}\left\{\Delta P_{L}(\mathrm{x}),\left|\Delta P_{E S}(\mathrm{x})\right|, p H(\mathrm{x})\right\} \#$

subject to $\mathbf{l} \leq \mathrm{x} \leq \mathbf{u} \#$

In models (13) and (14), $\mathbf{x}$ is the vector of decision variables representing the model inputs, namely the patientspecific parameters and the controls. The $\mathbf{l}$ and $\mathbf{u}$ represent lower and upper bounds on the inputs as defined in Table 3. These bounds were derived based on clinical experience. The absolute value around $\Delta P_{\mathrm{ES}}$ ensures that the objectives maximize and minimize the esophageal pressure swings, as esophageal pressure is negative.

To reduce the number of possible combinations of variables to examine, several were assigned a static nominal value (Table 4). These variables were chosen to remain static as they are either difficult to measure clinically, have minimal individual impact on the final model outputs, or are unlikely to vary greatly in the clinical setting. After fixing these variable values, the resulting vector $\mathbf{x}$ had dimension 
11 under pressure support and dimension ten under proportional assist.

Viewed as multi-objective optimization problems with three objective functions, our goal was to generate an approximate Pareto optimal set for models (13) and (14). The Pareto optimal set is defined as the set of "non-dominated" output values $\left\{\Delta P_{\mathrm{L}}(\mathbf{x}),\left|\Delta P_{\mathrm{ES}}(\mathbf{x})\right|, \mathrm{pH}(\mathbf{x})\right\}$, i.e., those that cannot be improved upon simultaneously in all three indicators and where improvement in any one of the indicators necessarily results in a degradation in the others. Since the objective functions are highly nonlinear functions of the decision variables $\mathbf{x}$, a local neighborhood search method was employed to solve both models (see Online Resource $3.3)$.

(a)

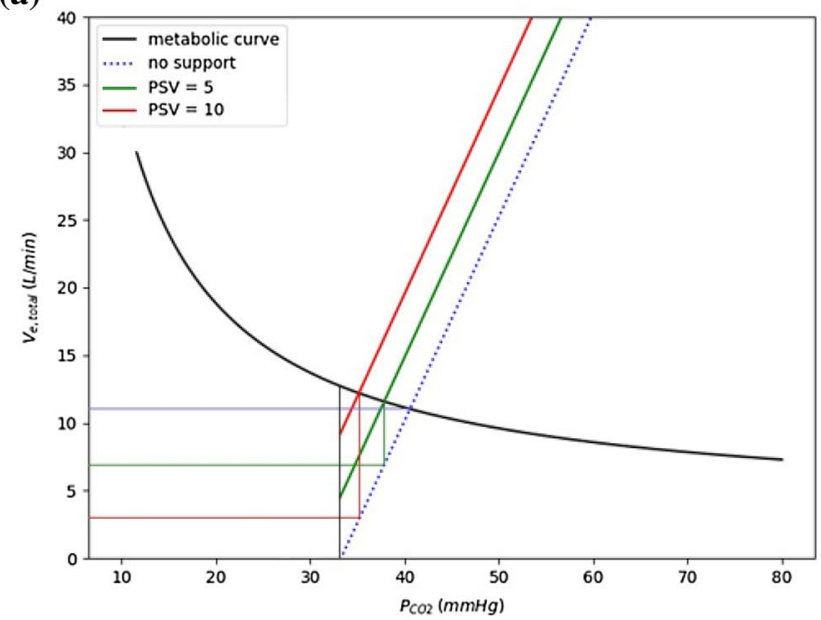

(c)

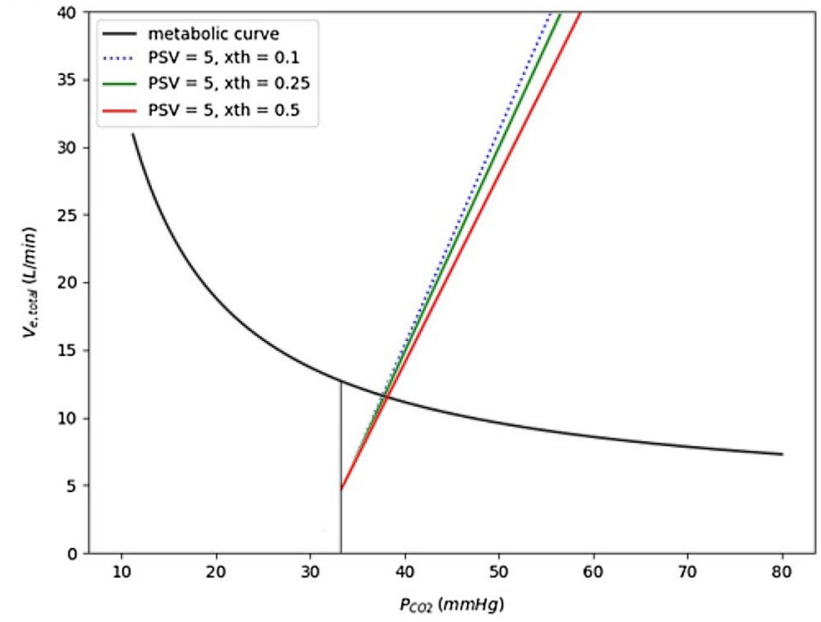

Fig. $8 P_{\mathrm{CO} 2}$ response curve a under pressure support ventilation $\mathbf{b}$ under proportional assist ventilation $\mathbf{c}$ under pressure support when flow-cycle threshold is modified by adjusting the flow-cycle propor-

\subsection{Simulation results}

Figure 8a-d show the $\mathrm{CO}_{2}$ response curve resulting from the model simulation using the nominal patient parameters. Several levels of ventilatory assist and propofol concentrations were simulated. Increasing pressure support induces a parallel shift in the simulated respiratory response (Fig. 8a), while increasing proportional assist increased the slope of the simulated response (Fig. 8b). The slope of the pressure support response can be decreased by increasing the flow-cycle threshold (Fig. 8c). For both pressure support and proportional assist, the introduction of propofol decreased the slope of the $\mathrm{CO}_{2}$ response (Fig. 8d). All of the outputs generated from the local neighborhood search under pressure support ventilation for both the maximization and minimization problems are shown in Fig. 9a. Removing

(b)

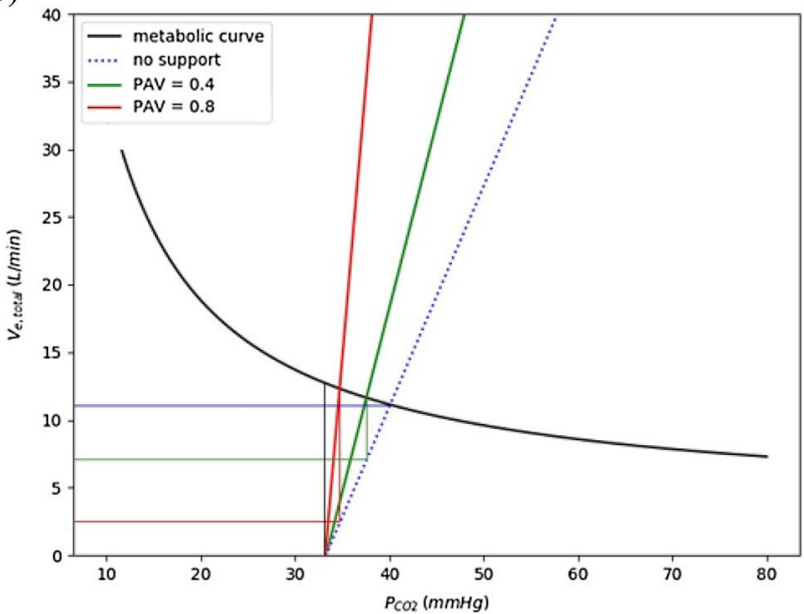

(d)

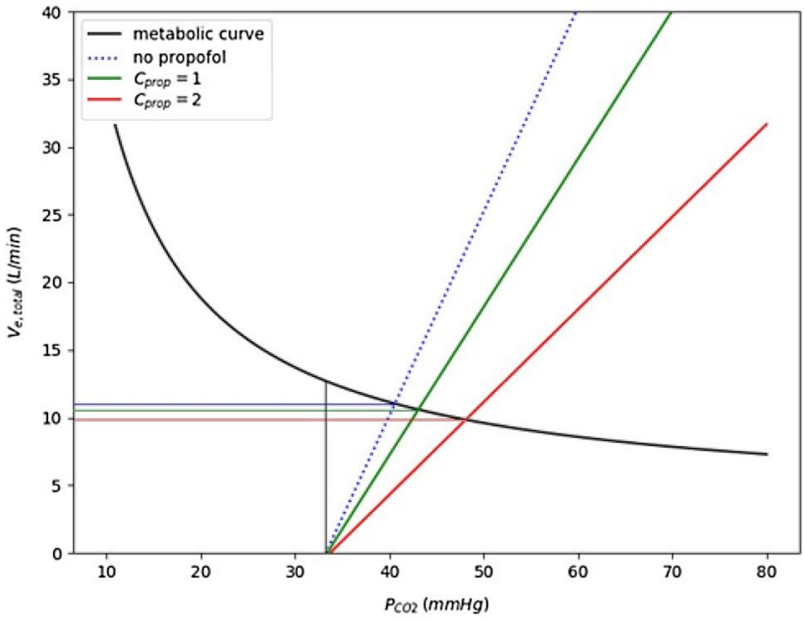

tion $\mathbf{d}$ when propofol is introduced. The effects of increased ventilator support or propofol concentration on $V_{\text {e,patient }}$ is shown using the thinner lines. The black vertical line indicates the apneic threshold 
(a)

- All saved outputs

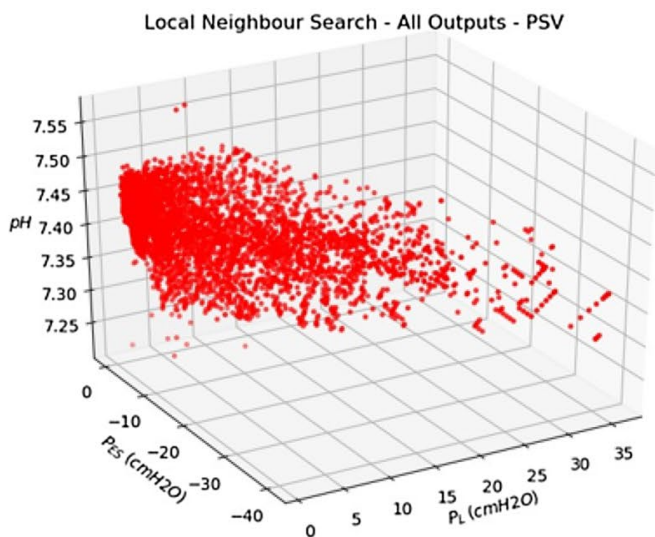

(c)

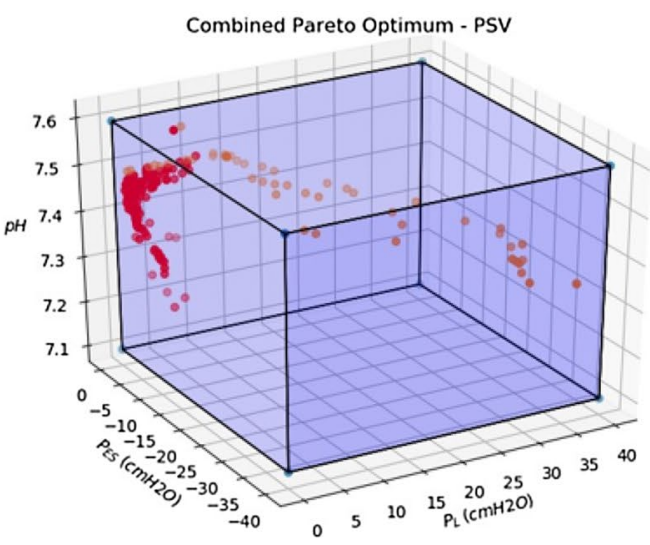

Fig. 9 All sets of $\left\{\Delta P_{\mathrm{L}}, \Delta P_{\mathrm{ES}}, \mathrm{pH}\right\}$ under a pressure support ventilation $\mathbf{b}$ proportional assist ventilation found through the local neighbor search for both maximization and minimization problems. Maximum and minimum Pareto-optimal fronts under $\mathbf{c}$ pressure support ventila-

Table 5 Ranges of the outputs obtained from simulations under both pressure support (PSV) and proportional assist (PAV)

\begin{tabular}{lll}
\hline Variable & $\mathrm{PSV}$ & $\mathrm{PAV}$ \\
\hline Ranges for simulation outputs & \\
$\Delta P_{\mathrm{L}}$ & $1.20-35.95 \mathrm{cmH}_{2} \mathrm{O}$ & $0.00-39.42 \mathrm{cmH}_{2} \mathrm{O}$ \\
$\Delta P_{\mathrm{ES}}$ & $0.00-40.55 \mathrm{cmH}_{2} \mathrm{O}$ & $0.00-37.73 \mathrm{cmH}_{2} \mathrm{O}$ \\
$\mathrm{pH}$ & $7.22-7.56$ & $7.22-7.49$ \\
\hline
\end{tabular}

the dominated points (points in which all three output values $-\Delta P_{\mathrm{L}}, \Delta P_{\mathrm{ES}}, \mathrm{pH}$-are smaller than another existing point) results in the maximum and minimum frontiers shown in Fig. 9c. This figure also shows the range of physiologically plausible values for each output as the bounding box. Similar results can be seen for the outputs (b) All saved outputs

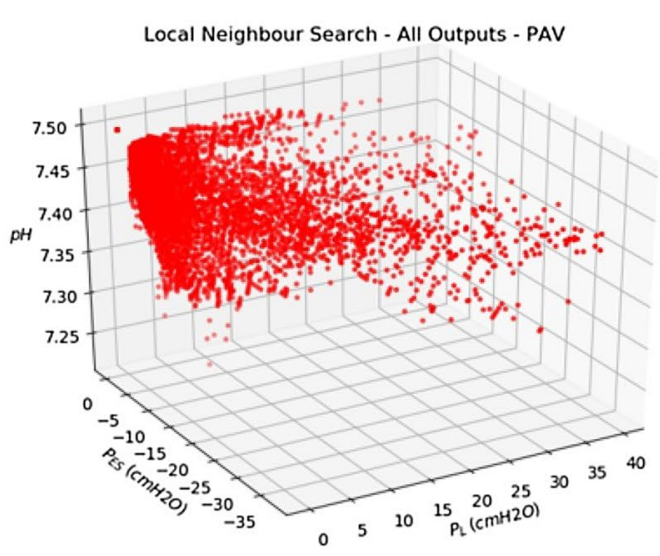

(d)

- Maximum Pareto front
- Minimum Pareto front

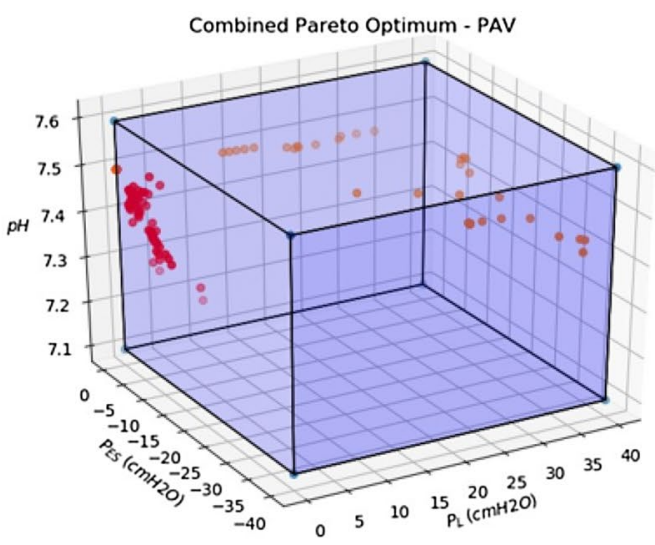

tion d proportional assist ventilation found through the local neighbor search. The box represents the set of plausible output values, determined through clinical experience

generated under proportional assist ventilation in Fig. 9b, d. As can be seen, the vast majority points forming the Pareto-optimal fronts lie within the bounding box, with the two offending points being marginally outside. Table 5 shows range of the outputs under both pressure support and proportional assist ventilation modes.

\section{Discussion}

\subsection{Model rationale}

The model presented in this paper, based on known ventilatory equations, provides the foundation for a CDSS designed to achieve lung- and diaphragm-protective mechanical ventilation. Although a CDSS requires much 
more than just a physiological model, the LDPV model is the first step towards a CDSS which aims to improve patient lung and diaphragm safety. The intermediate and final indicators of the model can also provide additional physiological insight into the patient's condition and disease-related respiratory derangements. This model is also the only one in literature to date to incorporate the effects of propofol and flow-cycle threshold, factors that are often present in the clinical setting.

In the LDPV model, the primary control parameters included are the mode of ventilation, the rate and duration of propofol infusion (Sect. 2.2), the level of inspiratory pressure to be applied by the ventilator (Sect. 2.4) and the flow-cycle proportion when the patient is receiving pressure support ventilation (Sect. 2.4.1). These inputs were chosen as the primary control parameters because both propofol and ventilatory support are routinely used to modulate patient respiration. Propofol depresses the patient's response to hypoxia and hypercapnia [19, 39]. The level of sedation patients receive can thus have a significant effect on their ventilatory response and their respiratory effort level $[20,21]$. Similarly, both modes of assisted ventilation included in the model have the primary goal of supporting patient ventilatory effort [34, 40], and are thus important for the model.

In our model, a patient's spontaneous ventilation is the sum of the central chemoreflex, peripheral chemoreflex, and wakefulness respiratory drives (which is zero while under anesthesia) as determined through a respiratory control model (Sect. 2.1). Using a respiratory control model allows us to establish a quantitative relationship between ventilator settings and respiratory effort [25]. Although the model is evaluated under steady-state conditions, determining both the central and peripheral chemoreflex drives is necessary as propofol, one of the chosen control parameters, only affects central chemoreflex receptors. Thus, the included respiratory control model was selected as it separates the impact of the central and peripheral chemoreflex drives on respiration, allowing the model to be more easily modified to include propofol. Furthermore, the selected model of respiratory control has been previously evaluated and fitted to testing results [41] and utilizes physiologically relevant parameters, which ensures that the overall model remains interpretable.

The Stewart model of acid-base was included in the model to ensure that the effects of metabolic acidosis and alkalosis are considered when adjustments are made to the controls. Maintenance of acid-base homeostasis is a primary goal of ventilation; therefore, the model must accurately estimate the effects of ventilation and sedation on $\mathrm{pH}$. The Stewart model was chosen as it provides a reliable quantitative approach to mathematical modelling of acid-base disorders [42] and has already been previously integrated into the selected respiratory control model by other investigators
[25]. The metabolic hyperbola and respiratory equation of motion (Sect. 2.5) are included in the LDPV model to relate the respiratory drives generated by the chemoreceptors to the respiratory response to $\mathrm{CO}_{2}$ [34], enabling identification of steady state ventilation conditions. The output indicators for lung and diaphragm protective ventilation $\left(\Delta P_{\mathrm{L}}, \Delta P_{\mathrm{ES}}\right)$ can then be easily determined.

Unlike many other mechanical ventilation models, the model presented does not describe pulmonary gas-exchange [11-13, 15]. A complex pulmonary gas-exchange system was deemed unnecessary for the LDPV model for several reasons:

Gas exchange is relatively easily managed and monitored using readily available clinical measurements [40].

The primary objective of the assisted ventilation modes incorporated into the model is to reduce a patient's respiratory effort rather than to optimize gas exchange $[34,40]$.

The LDPV model's output indicators are targeted solely towards improving lung and diaphragm safety rather than ensuring adequate oxygenation and gas-exchange.

Since the LDPV model does not describe pulmonary gas-exchange, it is somewhat less complex than other physiological models. While reduced complexity may result in the model being less physiologically accurate, it allows for the model outputs to be more easily interpreted and can provide clinicians with a clearer understanding of patient physiology. In addition, the model does not allow for the modification of positive-end expiratory pressure (PEEP). While modifying PEEP can influence respiratory effort, mechanics and gas exchange, it is highly unpredictable and to our knowledge, there is no existing mathematical model of the relationship between PEEP and respiratory drive. A future approach to incorporating PEEP into the LDPV model may require the integration of an empirical evaluation of patient response to PEEP.

The LDPV model is one of the only mechanical ventilation models that incorporates chemoreflex respiratory control. The INVENT system [12] adapts the same respiratory control model but determines the hydrogen ion concentrations affecting each chemoreceptor. In the INVENT system, central chemoreceptor drive is dependent on cerebrospinal fluid (CSF) hydrogen ion concentrations while peripheral chemoreceptor drive is dependent on arterial hydrogen ion concentration. This increases the complexity of the system as a CSF acid-base model is necessary, in addition to the model for blood acid-base. Furthermore, while the increased specificity may improve system accuracy, it also introduces additional assumptions and limitations. In INVENT, the CSF strong ion difference is assumed to be a constant value estimated from venous blood bicarbonate. In addition, CSF hydrogen ion concentration is dependent on cerebral blood flow, which can change in response to changes in the bicarbonate concentration or arterial $\mathrm{CO}_{2}$ pressure and this 
variation is not accounted for by the CSF acid-base model [43]. In contrast, the respiratory control model presented here is adapted directly [25] and accounts for the difference between the central and peripheral chemoreceptors only using the receptor thresholds. This greatly simplifies the overall model and does not introduce any additional assumptions or limitations, but likely increases simulation error (though the significance of such error is likely to be low as the model outputs are seen to be relatively insensitive to receptor thresholds).

The effect of propofol, or sedation in general, on respiratory effort has not previously been incorporated in a ventilation model or clinical decision support system. Since propofol has a clinically important effect on respiratory effort [20, 21], and is often used as a sedative in the management of critically ill patients [44], its inclusion enhances the clinical relevance of the model. In addition, the LDPV model uses a flow-cycle threshold based on patient generated flow when simulating pressure support ventilation, a feature that has not been incorporated previously. Such a threshold ensures that any changes in patient effort levels lead to an appropriate response from the ventilator. It was an important feature to include as it was seen to have a significant impact on patient effort (see Online Resource 4.2, Fig. 15).

Finally, the LDPV model is unique in that the outputs of the model directly reflect patient effort and can potentially be used as indicators of lung and diaphragm stress and strain. While previous ventilation models have included patient effort, they either do not incorporate them within a physiology-based model [44] or use a simplified measure based on the questionable assumption that a ratio of tidal volume and pressure support level can be used to describe patient effort $[12,43]$. The model could be implemented as a CDSS to help clinicians rapidly identify the combination of ventilation and sedation settings most likely to achieve lung and diaphragm-protective targets in patients, overcoming the complexity and time-consumption involved in titrating ventilation and sedation to target by trial and error.

\subsection{Model simulations and robustness}

The simulations demonstrate that our model describes a $\mathrm{CO}_{2}$ respiratory response comparable to that found in the literature. Figure $8 \mathrm{a}, \mathrm{b}$ shows that an increase in pressure support induces a parallel shift of the ventilatory response to $\mathrm{CO}_{2}$ to the left while an increase in proportional assist increases the slope of the response. Figure $8 \mathrm{c}, \mathrm{d}$ show that an increase in the flow-cycle proportion or sedation level in the model leads to a decrease in the slope of the response. The general directions of these responses correspond well to those found in the literature [20,34]. The magnitude of the responses as they relate to minute ventilation are also similar with what has been previously observed [21,34]. Although nominal patient parameters are used to simulate the $\mathrm{CO}_{2}$ respiratory response, these parameters have minimal effect on the general directions and magnitudes of the responses.

The simulated effect of control parameters on the target output indicators also compares well to what has previously been observed. Pressure support is seen to increase the static transpulmonary pressure swing, while decreasing the magnitude of the esophageal pressure swing and thus decreasing patient effort (Online Resource 4, Fig. 1) [36, $45,46]$. Increases in pressure support also slightly raise blood $\mathrm{pH}$ [45]. Similar relations have been observed in the simulation under proportional assist (Online Resource 4, Fig. 2) $[36,45]$. While under pressure support ventilation, the flow-cycle threshold decreases the amount of ventilator support provided. Hence flow-cycle proportion and pressure support have opposite effects on the output indicators (Online Resource 4, Fig. 3). Increasing levels of propofol have also been associated with decreasing the respiratory effort [21] and lowering blood pH (Online Resource 4, Fig. 4) [47-49].

Regarding model robustness, for the outputs to remain physiologically plausible, the target indicators must remain within the previously defined limits. Figure $9 \mathrm{c}, \mathrm{d}$ and Table 5 indicate that the target outputs from the pressure support simulations almost always lie within the defined physiologically plausible ranges. Overall, the simulation results demonstrate the robustness of the LDPV model. The results show that, for any set of clinically relevant inputs, the LDPV model will produce a set of outputs that are (at the very least) physiologically plausible. The results of the simulation also illustrate the range of possible outputs of the model; all model outputs are predicted to lie between the maximum and minimum Pareto fronts depicted. Although only 100 iterations were performed for each objective, the outputs of the simulation covered a wide range of values. Furthermore, the simulation considered all possible combinations of inputs, including combinations that may not even be physiologically plausible. While several parameters used static nominal values to reduce computational complexity, the model outputs can be seen to have low sensitivity to these parameters. Hence, using static values for these parameters should a low impact on the maximum and minimum Pareto fronts.

\subsection{Limitations}

Although the model has been shown to induce responses comparable to what is found in the literature and is robust across a wide range of clinically relevant patient parameters, several key limitations exist. 


\subsubsection{Assumptions present in system components}

Since the model was built by combining existing ventilatory equations, any predictions made using the model are contingent on the assumptions upon which these equations are built. Hence, if the assumptions of any system component are violated, predictions made using the model may be inaccurate.

\subsubsection{Relationship between propofol concentration and receptor sensitivity}

In the current version of the model, the regression equation that links the pharmacokinetic model to the respiratory drive model relies on an extremely limited data set. While it is clear that propofol has a significant clinical effect on central respiratory drive and effort [19, 21, 50], the exact relationship remains uncertain. Obtaining additional clinical data can help better elucidate this relationship.

\subsubsection{Respiratory frequency as an input}

Since the model uses respiratory frequency as a model input, it relies on the assumption that the respiratory frequency remains relatively constant during any incremental adjustment of the controls. Although evidence suggests that increases in inspiratory pressure support affect respiratory rate only minimally $[34,51]$, there is no known mathematical equation that governs this interaction. Additional clinical data can be used to empirically explore this relationship and modify the model in the future.

\subsubsection{Hydrogen ion concentration assumption}

In the original respiratory control model [25], the hydrogen ion concentration used to determine the central and peripheral chemoreflex drives are different due to the different locations of the chemoreceptors [25]. Separate acid-base models would be required to properly determine the hydrogen ion concentrations affecting each chemoreceptor. However, to simplify the LDPV model, these concentrations are assumed to be the same and any difference would be accounted for by the different receptor thresholds. If the thresholds are not selected properly, this assumption can result in estimation error. However, the significance of this error is likely to be low as the model outputs can be seen to be relatively insensitive to the threshold values (see Online Resource 4.2).

\subsubsection{Many input parameters}

To initialize the model, many patient-specific parameters are required. While many of these parameters (age, height, respiratory frequency, etc.) are captured via normal clinical assessment and do not require any invasive measurements, some parameters, such as propofol concentration or chest wall mechanics, are not typically or easily assessed. By requiring too many input parameters, the LDPV model and its associated CDSS might prove difficult to implement in the clinical setting. However, as shown in Online Resource 4.2, the output indicators are insensitive to many patient-specific parameters.

Several possible approaches can be taken to address this limitation. One possible approach is to use the LDPV to simulate outputs from a selected number of the more difficult to measure inputs and then use these input-output pairs in a supervised machine learning model that predicts these inputs from the clinical outputs. A welltrained machine learning model should be able to predict reasonable values for these inputs given measurements of a patient's $\mathrm{P}_{L}, \mathrm{P}_{\mathrm{ES}}$ and $\mathrm{pH}$. These inputs can then be used in the LDPV model to help guide subsequent decisions. An alternative approach is to use the LDPV model to explore in greater detail the sensitivity of the clinical outputs on the difficult to measure inputs. If certain inputs do not significantly impact the model outputs, it might also be possible to use nominal values for these inputs for subsequent modelling and decision support.

\section{Conclusion}

The LDPV model is a physiological model that may form the backbone of a CDSS focusing on lung and diaphragm protection during mechanical ventilation. The model considers respiratory drive, pharmacokinetics of propofol, acid-base homeostasis, ventilator settings and lung and respiratory muscle mechanics. It differs from existing mechanical ventilation models by focusing on output indicators that are most directly reflect lung and diaphragm safety [18, 22-24], incorporating effects of sedation, and including a flow-cycle threshold. Initial simulations produced results which demonstrate that outputs physiological responses consistent with what is expected. Sensitivity analysis showed that the output indicators are appropriately sensitive to the chosen control parameters. A robustness simulation showed that for any possible combination 
of input patient parameters, the model estimates output indicators that remain physiologically plausible.

Funding This research was supported in part by an EMHSeed Grant, funded by the Faculty of Applied Science and Engineering, Faculty of Medicine, and Department of Mechanical and Industrial Engineering at the University of Toronto, and the University Health Network. Dr. Goligher is supported by an Early Career Investigator Award from the Canadian Institutes of Health Research.

\section{Compliance with ethical standards}

Conflict of interest The authors declare that they have no conflict of interest.

\section{References}

1. Marini JJ. Mechanical ventilation: past lessons and the near future. Crit Care. 2013;17(Suppl 1):1-10. https://doi.org/10.1186/cc114 99.

2. Karcz M, Vitkus A, Papadakos PJ, Schwaiberger D, Lachmann B. State-of-the-art mechanical ventilation. J Cardiothorac Vasc Anesth. 2012;26(3):486-506. https://doi.org/10.1053/j. jvca.2011.03.010.

3. Goligher EC, Dres M, Fan E, Rubenfeld GD, Scales DC, Herridge MS, Vorona S, Sklar MC, Rittayamai N, Lanys A, Murray A, Brace D, Urrea C, Reid WD, Tomlinson G, Slutsky AS, Kavanagh BP, Brochard LJ, Ferguson ND. Mechanical ventilation-induced diaphragm atrophy strongly impacts clinical outcomes. Am J Respir Crit Care Med. 2018;197(2):204-13. https:// doi.org/10.1164/rccm.201703-0536OC.

4. Yoshida T, Fujino Y, Amato MB, Kavanagh BP. Fifty years of research in ards spontaneous breathing during mechanical ventilation risks, mechanisms, and management. Am J Respir Crit Care Med. 2017;195(8):985-92. https://doi.org/10.1164/rccm.20160 4-0748CP.

5. Gajic O, Dara SI, Mendez JL, Adesanya AO, Festic E, Caples SM, Rana R, St Sauver JL, Lymp JF, Afessa B, Hubmayr RD. Ventilator-associated lung injury in patients without acute lung injury at the onset of mechanical ventilation. Crit Care Med. 2004;32(9):1817-24. https://doi.org/10.1097/01.CCM.00001 33019.52531 .30 .

6. Marewski JN, Gigerenzer G (2012) Heuristic decision making in medicine. Dialogues Clin Neurosci. 14(1):77-89, https://doi. org/10.1038/jid.2015.269, arXiv:1011.1669v3

7. McKinley BA, Moore FA, Sailors RM, Cocanour CS, Marquez A, Wright RK, Tonnesen AS, Wallace CJ, Morris AH, East TD. Computerized decision support for mechanical ventilation of trauma induced ARDS: results of a randomized clinical trial. J Trauma Injury Infect Crit Care. 2001;50(3):415-25. https://doi. org/10.1097/00005373-200103000-00004.

8. Kwok HF, Linkens DA, Mahfouf M, Mills GH. Rule-base derivation for intensive care ventilator control using ANFIS. Artif Intell Med. 2003;29(3):185-201. https://doi.org/10.1016/S0933 3657(02)00074-X.

9. Dojat M, Harf A, Touchard D, Lemaire F, Brochard L. Clinical evaluation of a computer-controlled pressure support mode. Am J Respir Crit Care Med. 2000;161(4):1161-6.
10. Tehrani FT, Roum JH. Intelligent decision support systems for mechanical ventilation. Artif Intell Med. 2008;44(3):171-82. https ://doi.org/10.1016/j.scienta.2009.07.014.

11. Wang A, Mahfouf M, Mills GH, Panoutsos G, Linkens DA, Goode K, Kwok HF, Dena 1 M (2010) Intelligent model-based advisory system for the management of ventilated intensive care patients. Part II: advisory system design and evaluation. Comput Methods Programs Biomed. 99(2):208-217, https://doi.org/10.1016/j. cmpb.2010.03.009

12. Rees SE, Karbing DS. Determining the appropriate model complexity for patient-specific advice on mechanical ventilation. Biomed Tech. 2017;62(2):183-98. https://doi.org/10.1515/ bmt-2016-0061.

13. Tehrani FT, Abbasi S. A model-based decision support system for critiquing mechanical ventilation treatments. J Clin Monit Comput. 2012;26(3):207-15. https://doi.org/10.1007/s1087 7012-9362-0.

14. Das A, Menon PP, Hardman JG, Bates DG. Optimization of mechanical ventilator settings for pulmonary disease states. IEEE Trans Biomed Eng. 2013;60(6):1599-607. https://doi. org/10.1109/TBME.2013.2239645.

15. Hardman JG, Bedforth NM, Ahmed AB, Mahajan RP, Aitkenhead AR. A physiology simulator: validation of its respiratory components and its ability to predict the patient's response to changes in mechanical ventilation. $\mathrm{Br} \mathrm{J}$ Anaesth. 1998;81(3):327-32. https://doi.org/10.1093/bja/81.3.327.

16. Karbing DS, Spadaro S, Dey N, Ragazzi R, Marangoni E, Dalla Corte F, Moro F, Lodahl D, Hansen NS, Winding R, Rees SE, Volta CA. An open-loop, physiologic model-based decision support system can provide appropriate ventilator settings. Crit Care Med. 2018;46(7):e642-e648648. https://doi.org/10.1097/ CCM.0000000000003133.

17. Spardro S, Karbing DS, Dalla Corte F, Mauri T, Moro F, Gioia A, Volta CA, Rees SE. An open-loop, physiological model based decision support system can reduce pressure support while acting to preserve respiratory muscle function. J Crit Care. 2018;48:407-13. https://doi.org/10.1016/j. jerc.2018.10.003.

18. Goligher EC, Brochard LJ, Reid WD, Fan E, Saarela O, Slutsky AS, Kavanagh BP, Rubenfeld GD, Ferguson ND. Diaphragmatic myotrauma: a mediator of prolonged ventilation and poor patient outcomes in acute respiratory failure. Lancet Respir Med. 2018. https://doi.org/10.1016/S2213-2600(18)30366-7.

19. Nieuwenhuijs D, Sarton E, Teppema LJ, Kruyt E, Olievier I, van Kleef J, Dahan A. Respiratory sites of action of propofol. Anesthesiology. 2001;95(4):889-95.

20. Nieuwenhuijs DJF, Olofsen E, Romberg RR, Sarton E, Ward D, Engbers F, Vuyk J, Mooren R, Teppema LJ, Dahan A. Response surface modeling of remifentanil-propofol interaction on cardiorespiratory control and bispectral index. Anesthesiology. 2003;777:777. https://doi.org/10.1097/00000542-2003020000 0008.

21. Vaschetto R, Cammarota G, Colombo D, Longhini F, Grossi F, Giovanniello A, Della Corte F, Navalesi P. Effects of propofol on patient-ventilator synchrony and interaction during pressure support ventilation and neurally adjusted ventilatory assist. Crit Care Med. 2014;42(1):74-82. https://doi.org/10.1097/ CCM.0b013e31829e53dc.

22. Bugedo G, Retamal J, Bruhn A (2017) Driving pressure: a marker of severity, a safety limit, or a goal for mechanical ventilation? Crit Care 21(1):199, https://doi.org/10.1186/s1305 4-017-1779-x 
23. Goligher EC, Ferguson ND, Brochard LJ. Clinical challenges in mechanical ventilation. The Lancet. 2016;387(10030):1856-66. https://doi.org/10.1016/S0140-6736(16)30176-3.

24. Talmor DS, Fessler HE. Are esophageal pressure measurements important in clinical decision making in mechanically ventilated patients? Respir Care. 2010;. https://doi.org/10.1056/NEJMr a1203367.

25. Duffin J (2005) Role of acid-base balance in the chemoreflex control of breathing. J Appl Physiol. 99(6):2255-2265, https://doi. org/10.1007/s10891-012-0641-x, https://jap.physiology.org/cgi/ doi/10.1152/japplphysiol.00640.2005

26. Eleveld DJ, Colin P, Absalom AR, Struys MM. Pharmacokineticpharmacodynamic model for propofol for broad application in anaesthesia and sedation. Br J Anaesth. 2018;120(5):942-59. https ://doi.org/10.1016/j.bja.2018.01.018.

27. Antonogiannaki EM, Mitrouska I, Amargianitakis V, Georgopoulos D. Evaluation of acid-base status in patients admitted to ED-physicochemical vs traditional approaches. Am J Emerg Med. 2015;33(3):378-82. https://doi.org/10.1016/j.ajem.2014.12.010.

28. Morgan T. The Stewart approach-one clinician's perspective. Clin Biochem Rev. 2009;30(2):41-544. https://doi.org/10.1016/j. jcrc.2013.06.005.

29. Figge J, Mydosh T, Fencl V. Serum-Proteins and acid-base equilibria —a follow-up. J Lab Clin Med. 1992;120:713-9.

30. Meza S, Mendez M, Ostrowski M, Younes M. Susceptibility to periodic breathing with assisted ventilation during sleep in normal subjects. J Appl Physiol. 1998;. https://doi.org/10.1152/jappl 1998.85.5.1929.

31. Sassoon C. Triggering of the ventilator in patient-ventilator interactions. Respir Care. 2011;56(1):39-51.

32. Pardo M (2012) Mechanical and noninvasive ventilation, 5th edn. Elsevier, New York, https://doi.org/10.1016/B978-0-323-08500 $-7.00010-2$

33. Yamada Y, Du HL (2000) Analysis of the mechanisms of expiratory asynchrony in pressure support ventilation: a mathematical approach. J Appl Physiol 88(6):2143-50, doi:10.1152/ jappl.2000.88.6.2143, https://www.ncbi.nlm.nih.gov/pubme $\mathrm{d} / 10846029$

34. Tobin M, editor. Principles and practice of mechanical ventilation, 3rd editedn. Chicago: McGraw-Hill; 2013.

35. Nava S, Fanfulla F. Non invasive artificial ventilation. Springer, Berlin, 2014. https://doi.org/10.1007/978-88-470-5526-1.

36. Akoumianaki E, Maggiore SM, Valenza F, Bellani G, Jubran A, Loring SH, Pelosi P, Talmor D, Grasso S, Chiumello D, Gue Rin C, Patroniti N, Ranieri VM, Gattinoni L, Nava S, Terragni PP, Pesenti A, To-bin M, Mancebo J, Brochard L. The application of esophageal pressure measurement in patients with respiratory failure. Am J Respir Crit Care Med. 2014;189(5):520-31. https:// doi.org/10.1164/rccm.201312-2193CI.

37. Morris MD. Factorial sampling plans for preliminary computational experiments. Technometrics. 1991;. https://doi. org/10.1080/00401706.1991.10484804.

38. Campolongo F, Cariboni J, Saltelli A. An effective screening design for sensitivity analysis of large models. Environ Modell Softw. 2007; . https://doi.org/10.1016/j.envsoft.2006.10.004

39. Blouin RT, Seifert HA, Babenco HD, Conard PF, Gross JB. Propofol depresses the hypoxic ventilatory response during conscious sedation and is hypercapnia. Anesthesiology. 1993;. https ://doi.org/10.1097/00000542-199312000-00007.

40. Ambrosino N, Rossi A. Proportional assist ventilation (PAV): a significant advance or a futile struggle between logic and practice? Thorax. 2002;57(3):272-6. https://doi.org/10.1136/thora x.57.3.272.

41. Duffin J. The role of the central chemoreceptors: a modeling perspective. Respir Physiol Neurobiol. 2010;173(3):230-43. https:// doi.org/10.1016/j.resp.2010.03.010.

42. Corey HE. Stewart and beyond: new models of acid-base balance. Kidney Int. 2003;64(3):777-87. https://doi.org/10.104 6/j.1523-1755.2003.00177.x.

43. Larraza S, Dey N, Karbing DS, Jensen JB, Nygaard M, Winding $\mathrm{R}$, Rees SE. A mathematical model approach quantifying patients' response to changes in mechanical ventilation: evaluation in pressure support. J Crit Care. 2015;30(5):1008-155. https ://doi.org/10.1016/j.jcrc.2015.05.010.

44. Banner MJ, Euliano NR, MacIntyre NR, Layon AJ, Bonett S, Gentile MA, Bshouty Z, Peters C, Gabrielli A. Ventilator advisory system employing load and tolerance strategy recommends appropriate pressure support ventilation settings: Multisite validation study. Chest. 2008;133(3):697-703. https://doi.org/10.1378/chest .07-2011.

45. Passam F, Hoing S, Prinianakis G, Siafakas N, Milic-Emili J, Georgopoulos D. Effect of different levels of pressure support and proportional assist ventilation on breathing pattern, work of breathing and gas exchange in mechanically ventilated hypercapnic COPD patients with acute respiratory failure. Respiration. 2003;70(4):355-61. https://doi.org/10.1159/000072897.

46. Clement KC, Courtney S, Dargaville PA, Heulitt M, Khemani RG, Newth CJ, Rimensberger PC, Tingay D. Respiratory mechanics in the mechanically ventilated patient. In: Rimensberger PC, editor. Pediatric and neonatal mechanical ventilation: from basics to clinical practice. Berlin: Springer; 2015. p. 293-371.

47. Kim JY, Lee D, Lee KC, Choi JJ, Kwak HJ. Stewart's physicochemical approach in neurosurgical patients with hyperchloremic metabolic acidosis during propofol anesthesia. J Neurosurg Anesthesiol. 2008;20(1):1-7. https://doi.org/10.1097/ANA.0b013 e3181483ddd.

48. Choi YJ, Kim MC, Lim YJ, Yoon SZ, Yoon SM, Yoon HR. Propofol infusion associated metabolic acidosis in patients undergoing neurosurgical anesthesia: a retrospective study. J Korean Neurosurg Soc. 2014;56(2):135-40. https://doi.org/10.3340/ jkns.2014.56.2.135.

49. Cravens GT, Packer DL, Johnson ME. Incidence of propofol infusion syndrome during noninvasive radiofrequency ablation for atrial flutter or fibrillation. Anesthesiology. 2007;106(6):1134-8.

50. Liu L, Wu AP, Yang Y, Liu SQ, Huang YZ, Xie JF, Pan C, Yang CS, Qiu HB. Effects of propofol on respiratory drive and patient-ventilator synchrony during pressure support ventilation in postoperative patients: a prospective study. Chin Med J. 2017;130(10):1155-60. https://doi.org/10.4103/0366-6999.20586

51. Giannouli E, Webster K, Roberts D, Younes M. Response of ventilator-dependent patients to different levels of pressure support and proportional assist. Am J Respir Crit Care Med. 1999;. https ://doi.org/10.1164/ajrccm.159.6.9704025.

Publisher's Note Springer Nature remains neutral with regard to jurisdictional claims in published maps and institutional affiliations. 